\title{
Nano-Surfactants and Enhancement of their Detergency
}

\author{
Poonam Ghodke ${ }^{1}$, Dr. (Mrs.) Swarda Mote ${ }^{2}$ \\ Graduate, B. Tech in Chemical Engg, Priyadarshini Institute of Engg and Technology, Nagpur, Maharashtra, India ${ }^{1}$ \\ Associate Professor, Department of Chemical Engg, Priyadarshini Institute of Engg and Technology, Nagpur, \\ Maharashtra, India ${ }^{2}$
}

\begin{abstract}
Surfactants have been a crucial subject of investigation since the genesis of life. These smart chemicals are very well known for their surface tension reducing abilities and thus find a diverse scope in essential industrial applications such as in day-to-day toiletries, cosmetics and pharmaceutics. Above Critical Micelle Concentration (CMC), the surfactants form Nano-sized particles called as the micelles which are responsible for the entrapment and cleaning of the dirt. Many production firms especially the detergent formulating industry thrive on this mechanism. Surfactants being the costliest ingredient, the major concern of the detergent manufacturing industries is related to the quantity as well as the expected efficiency of these chemicals. However, one can observe a slight anomaly in the anticipated efficacy of the Nano-surfactants (Nano-sized surfactant micelles). This paper emphasizes on how the hardness present in the water is the cause for such eccentric behaviour of these chemicals. Clinging to the costeffectiveness, this study also employs a comparison between various Builders which are used in order to control the hardness in the water thus gaining the desired results. An attempt has been made to upsurge the detergency with the aid of Builders altogether enhancing coherence and effectiveness.
\end{abstract}

Keywords: Surface tension, Critical Micelle Concentration (CMC), Nano-Surfactants, Hardness of water, Builders, Detergency

\section{INTRODUCTION}

The term "Surfactants" is derived as a diminution to the Surface-Active Agents which are responsible for minimizing the surface tension of aqueous media and interfacial tension between liquid-liquid and liquid-solid systems. Due to this phenomenon, surfactants exhibit versatile important industrial applications such as laundry detergents, personal toiletries and home cleaning caches. The rudimentary structure of the surfactants consists of both hydrophilic and hydrophobic moieties that eventually engage in the formation of micelles at Critical Micelle Concentration (CMC). This encourages the process of entrapment thus eliminating the undesired fat and dirt. CMC is a key parameter for the surfactants. It indicates the usually narrow range of concentrations separating the limits, below which most of the surfactant is in the monomeric state and above which virtually all additional surfactant enters the micellar state [1]. Sizes of micelles range from $2 \mathrm{~nm}(20 \mathrm{~A})$ to $20 \mathrm{~nm}(200 \mathrm{~A})$, depending on composition and concentration. The average size of the surfactant package micelles is $80 \mathrm{~nm}$ with a range of 20-200 $\mathrm{nm}$ [9].

Owing to the size of the micelles, it is convenient to say that the "Nano-surfactants" are equipped with sophisticated mechanism and so the presumed efficiency of these chemicals are supposed to be apt but there is a marginal deviation from the theory. In spite of the fact that surfactant science is a matured discipline, there is still room for advancement in the detergency. Surfactants being the vital ingredient, the detergent formulating industries consume large volumes of surfactants for manufacturing detergents. The major concern that these businesses face is the high cost of this commodity and the slight inefficiency in their detergency. The objective of this study was to investigate the behaviour of the various surfactants by observing the presence of hardness in the water. Considering that hardness does affect the functioning of the surfactants, a comparative study of different Builders was conducted in order to gain a potent and cost-effective water softening agent thus addressing to the stagnated efficacy of the surfactants.

\section{METHOD AND MATERIALS}

A. Complexometric Titration: Complexometric titration is one of the best ways of measuring total water hardness. At $\mathrm{pH}$ around 10 EDTA easily reacts with both calcium and magnesium in the same molar ratio (1:1). Stability constant of calcium complex is a little bit higher, so calcium reacts first, magnesium later. Thus, for the end point, we should use the same indicator we use when titrating magnesium - that is Eriochrome Black T. In the case of water that doesn't 


\section{International Advanced Research Journal in Science, Engineering and Technology}

Vol. 5, Issue 9, September 2018

contain magnesium at all, to be able to detect end point we should add small amount of magnesium complex ${ }^{2+}$ MgEDTA. Calcium will be displaced by identical amount of magnesium, and it will be titrated later, not changing final result. However, this is a very rare situation [5]. Due to steric hindrances, EDTA will complex with calcium and magnesium in a one-to-one molar ratio. The indicator imparts a red color to the solution while there are calcium and magnesium ions that have not complexed with EDTA. Once the endpoint has been reached and there is no more uncomplexed $\mathrm{Ca}$ or $\mathrm{Mg}$, the indicator will give a blue color [4].

In order to prepare hard water of known hardness and to test the effect of the hardness on the various surfactant samples as well as builder samples, Hardness kit employing the drop count method was utilized. The kit works on the same principle as the Complexometric titra. It included $25 \mathrm{ml}$ measuring jar and three bottles. Bottles A, B and D-25 consisted of Eriochrome Black T (EBT), Ammoniacal buffer and Ethylenediaminetetraacetic acid (EDTA) respectively. To calculate the hardness in terms of $\mathrm{CaCO}_{3}$ the correlation, 1 drop $=25 \mathrm{ppm}$ was utilized. To calculate the hardness, hard water was taken in $25 \mathrm{ml}$ test jar with 10 drops of buffer and few specks of EBT indicator. EDTA are added dropwise to the solution till the colour changed from pink to blue and a count of the drops had to be noted. Using the correlation given above the hardness in water was determined. Note: This method was employed over the complexometric titration in order to reap accurate results and the tests were strictly conducted in the presence of permanent hardness since there is a need to reduce calcium and other metals to improve water hardness and allow the detergents to function well [10].

B. Preparation of Hard Water: $275 \mathrm{ppm}, 525 \mathrm{ppm}$ and $925 \mathrm{ppm}$ hard water were prepared for the experiment. $275 \mathrm{ppm}$ hard water can be prepared by adding $0.294 \mathrm{gm}$ of Dihydrated Calcium Chloride $\left(\mathrm{CaCl}_{2} .2 \mathrm{H} 2 \mathrm{O}\right)$ in 1 litre of distilled water. Similarly, the preparation of $525 \mathrm{ppm}$ and $925 \mathrm{ppm}$ hard water can achieved by adding $0.735 \mathrm{gm}$ and 1.470 gm of Dihydrated Calcium Chloride $\left(\mathrm{CaCl}_{2} .2 \mathrm{H} 2 \mathrm{O}\right)$ respectively in 1 litre of distilled water separately.

C. Determination of Hardness Left in Known Hard Water Sample after Addition of Surfactants: The following proportions result in the formation of $1 \%$ surfactant solution in known hard water samples also $25 \mathrm{ml}$ of each of these $1 \%$ solution of the surfactant were taken in the test jar and the drop count method was implemented to find the hardness left in the water. The following industrial surfactants samples were prepared: [12], [6], [11]. For LABSA 0.55gm of LABSA (90\% purity) was added in $50 \mathrm{ml}$ of $275 \mathrm{ppm}, 525 \mathrm{ppm}$ and $925 \mathrm{ppm}$ hard water respectively. Similarly, $0.5813 \mathrm{gm}$ of MES (86\% purity), $1.785 \mathrm{gm}$ of SLES liquid (28\% purity), $0.714 \mathrm{gm}$ of SLES paste (70\% purity), $0.588 \mathrm{gm}$ of SLS powder ( $85 \%$ purity), $1.3157 \mathrm{gm}$ of AOS (38\% purity), 1.42 gm of CAPB (35\% purity) and $0.55 \mathrm{gm}$ of LABSA ( $90 \%$ purity) were added in $50 \mathrm{ml}$ of known hard water samples respectively as well as separately.

D. Determination of Hardness Left in Known Hard Water Sample after Addition of Builders: $0.2 \%$ of builder solutions were prepared in water of known hardness by adding $0.1 \mathrm{gm}$ of builders in $50 \mathrm{ml}$ of $275 \mathrm{ppm}, 525 \mathrm{ppm}$ and $925 \mathrm{ppm}$ hardwater respectively. $25 \mathrm{ml}$ of this $0.2 \%$ solution of the builder was taken in the test jar and the drop count was implemented to find the hardness left in the water. Following are the builders utilised for the study: [3], [7], [8] Sodium Tripolyphosphate (STPP), Ethylenediaminetetraacetic acid (EDTA), Triethanolamine (TEA), Zeolite, Citric acid, $\mathrm{NaOH}$, Tetra sodium Pyrophosphate, Sodium Hexametaphosphate, Sodium Carbonate, Sodium Bicarbonate, Sodium Silicate, Borax and Calcium Hydroxide were utilised as the builders to be tested for the study.

E. Preparation of Detergent samples for Conducting the Whiteness and Efficiency Tests: Eventually, detergent samples along with citric acid as a builder were prepared in order to investigate the whiteness and detergency. Constituents [2], [3] of the detergent samples are as follow:

Sample 1: The sample was prepared with $12 \%$ active MES surfactant and $7 \mathrm{gm}$ of soda ash to obtain the detergent powder. In order to prepare the mix, $14.45 \mathrm{gm}$ of melted MES surfactant, 40.05gm salt, 35gm Dolomite and 3.16gm speckles were taken and stirred thoroughly with an addition of small quantity of CBS-X i.e roughly $0.14 \mathrm{gm}$ and perfume contributing a quantity of $0.2 \mathrm{gm}$.

Sample 2: A similar sample was prepared with $12 \%$ active MES surfactant and a slight increase in the soda ash to $10 \mathrm{gm}$ in order to obtain the detergent powder. To prepare the mix, $14.45 \mathrm{gm}$ of melted MES surfactant, $40.12 \mathrm{gm}$ of salt, $3 \mathrm{gm}$ speckles were taken and stirred thoroughly with an addition of CBS-X of $0.03 \mathrm{gm}$ and perfume contributing a quantity of $0.2 \mathrm{gm}$. The difference in the sample 1 and sample 2 is sample 2 consist of citric acid, which is about $1.02 \mathrm{gm}$.

Sample 3: This sample was prepared in the way same as sample 2 and sample 3 with $12 \%$ active MES surfactant and soda ash of about $10 \mathrm{gm}$ to obtain the detergent powder. To prepare the mix, $14.45 \mathrm{gm}$ of melted MES surfactant, $32 \mathrm{gm}$ of salt, 3.4gm of speckles were taken and stirred thoroughly with an addition of CBS-X of $0.1 \mathrm{gm}$ and perfume contributing a quantity of $0.2 \mathrm{gm}$. This sample has the highest amount of citric acid which was about $9 \mathrm{gm}$. 


\section{International Advanced Research Journal in Science, Engineering and Technology}

Vol. 5, Issue 9, September 2018

\section{RESULT AND DISCUSSION}

A. Effect of Hardness on surfactants present in the water:

The study to determine the effect of hardness on surfactant solutions involved the addition of the most commonly utilized surfactants in known hard water samples of three different ppm and was carried out on the same day for all the surfactant samples with the average temperature of $27-29^{\circ} \mathrm{C}$. The hardness left after the addition of 8 different surfactant samples of varied purity is demonstrated in the Figure 1.

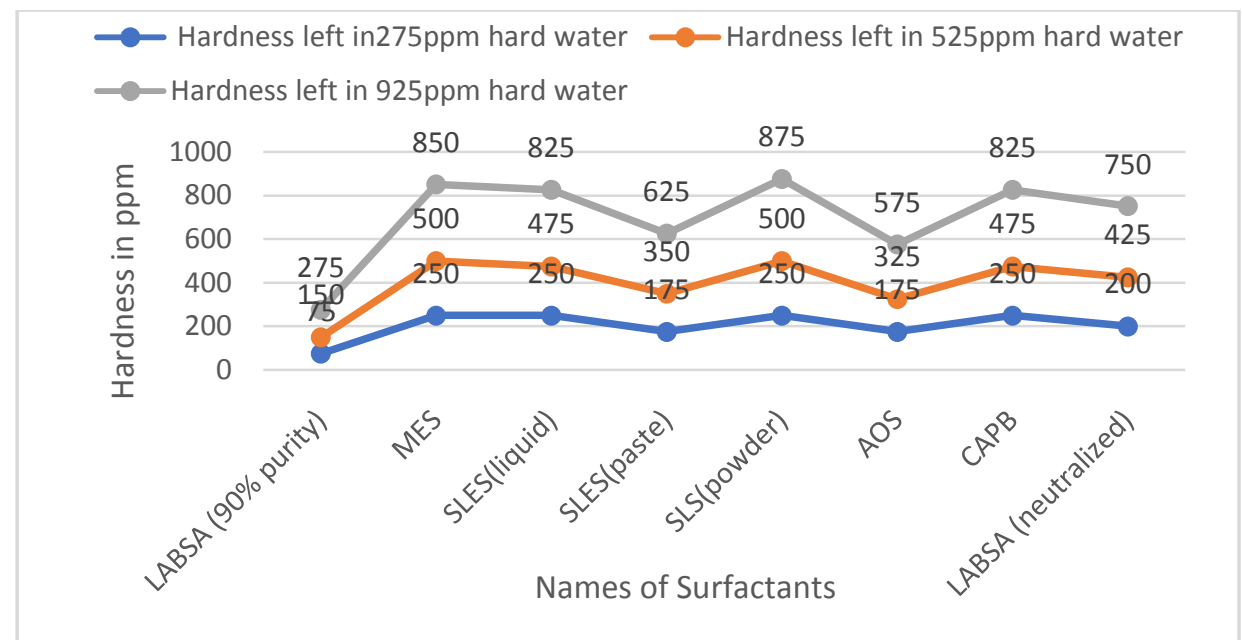

Fig 1. Hardness left in 275, 525 and 925 ppm water after the addition of different surfactants.

From the graph, one can infer that surfactants did contribute in the removal of hardness from the water which hindered them from their sole purpose and thus negatively affected the whiteness and detergency that presumably needed to be achieved. Observations also revealed that some surfactants like LABSA, SLES paste and AOS considerably lowered the permanent hardness of the water whereas, MES and SLS powder were slightly affected by the hardness and could be more often utilized for manufacturing detergents.

B. Performance of Builders in 275ppm, 525ppm and 925ppm Hard water:

The test on all Builders were done on the same day with an average temperature of about $27-30^{\circ} \mathrm{C}$. The graphical representation of the hardness extraction activity of 13 different Builders in 275 ppm hard water was illustrated in the Figure 2 below.

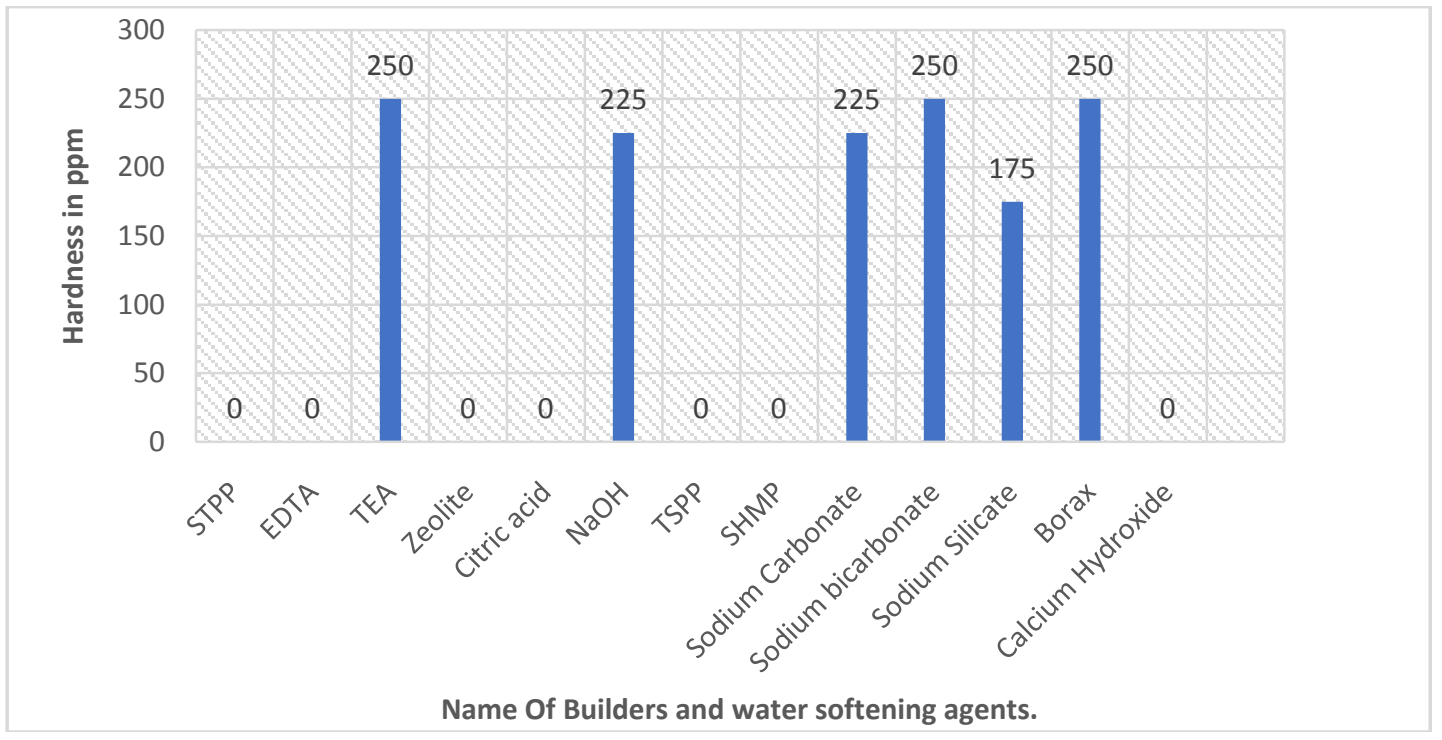

Fig 2. Hardness left in 275 ppm water sample after the addition of Builders.

On the basis of the graph, it was clear than most of the Builders which included STPP, EDTA, Zeolite, Citric acid, Tetra Sodium Pyrophosphate, Sodium Hexametaphosphate and Calcium hydroxide eliminated the hardness in 275ppm 


\section{International Advanced Research Journal in Science, Engineering and Technology}

Vol. 5, Issue 9, September 2018

hard water completely and could be tested for further increase in the hardness of the water. The graphical representation of the hardness extraction activity of 13 different Builders in 525 ppm hard water was illustrated in the Figure 3 below.

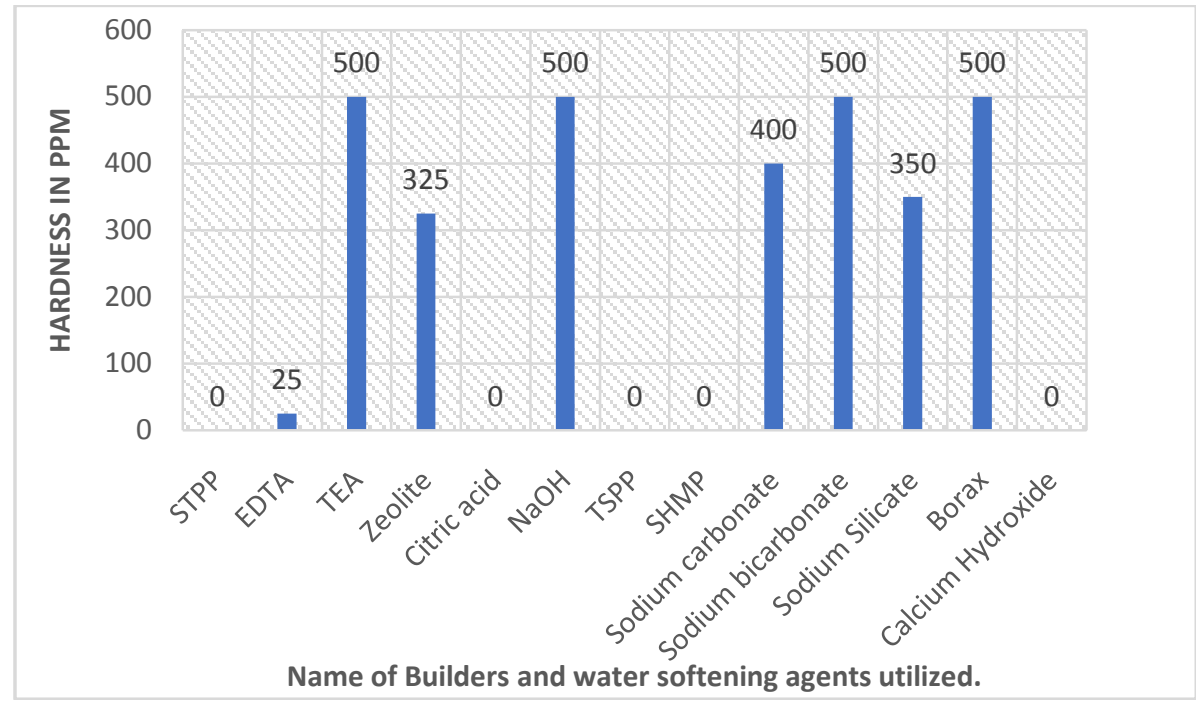

Fig 3. Hardness left in 525ppm water sample after the addition of Builders.

The illustrative graph above, shows that STPP, Citric acid, Tetra Sodium Pyrophosphate, Sodium Hexametaphosphate and Calcium hydroxide continued to proof their water softening ability by completely removing the presence of hardness in 525ppm water sample and that could be tested for higher level of hardness in the water. However, slight hardness was observed to be left while EDTA was used which equally proofed its usefulness in 525ppm water sample. The graphical representation of the hardness extraction activity of 13 different Builders in 925 ppm hard water was illustrated in the Figure 4 below.

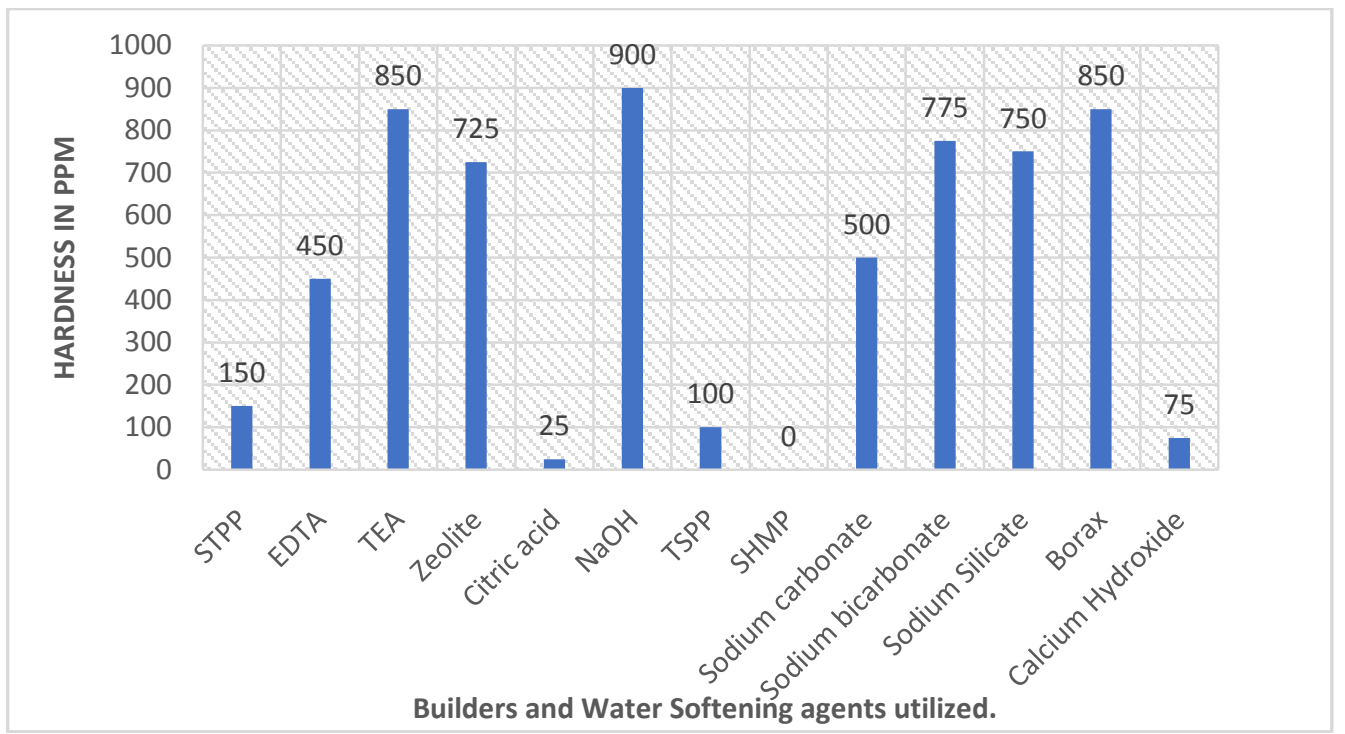

Fig 4. Hardness left in 925ppm water sample after the addition of Builders.

It was quite evident from the graph, that Sodium Hexametaphosphate was successful in removing complete hardness in water sample of $925 \mathrm{ppm}$. Marginal amount of hardness was observed while using Citric acid as a builder in the above water sample. On the hand, Calcium hydroxide and Tetra Sodium Pyrophosphate exhibited a sharp trend from nil to $75 \mathrm{ppm}$ and $100 \mathrm{ppm}$ hardness left in the water sample respectively.

C. Performance of the Prepared Detergent Samples with Citric acid as a Builder:

The effectiveness of the detergent samples was examined by the addition of Builder into the sample. Table I. and Figures 5, 6 and 7 Illustrate the progressive percentage wise increase in the concentration of Citric acid that in turn proliferated the whiteness of the cloth on which the tests were conducted. 


\section{International Advanced Research Journal in Science, Engineering and Technology}

Vol. 5, Issue 9, September 2018

Table I. The effect on detergency and whiteness of the surfactants by adding builders.

Sample Conc. of citric Values before Values before Values after Values afterOverall no. acid in the the test (front the test the test the test increase in

\begin{tabular}{|c|c|c|c|c|c|c|}
\hline & sample & face) & (rear face) & (front face) & (rear face) detergency \\
\hline 1 & $0 \%$ & 8.6 & 8.9 & 22.9 & 25.1 & 16.5 \\
\hline 2 & $1 \%$ & 10.3 & 9.9 & 27.1 & 27.1 & 17.2 \\
\hline 3 & $9 \%$ & 8.4 & 9 & 29.6 & 30.1 & 21.2 \\
\hline
\end{tabular}

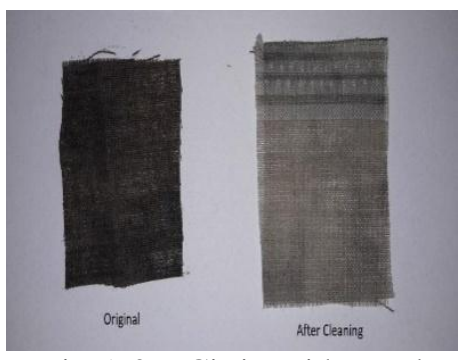

Fig 5. 0\% Citric acid sample

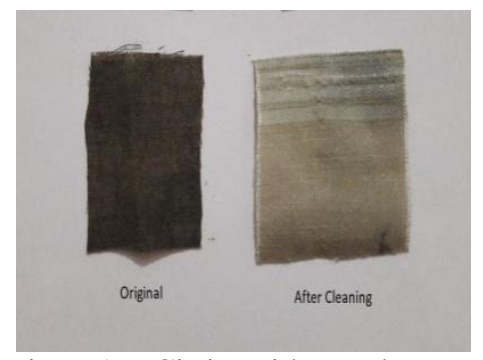

Fig 6. 1\% Citric acid sample

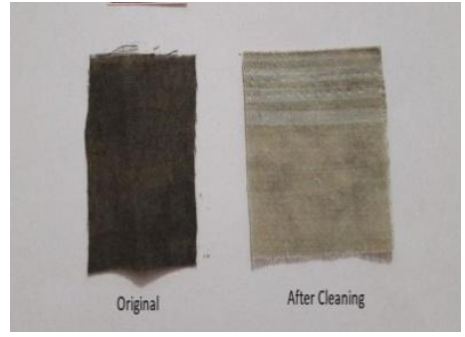

Fig 7. 9\% Citric acid sample

The observations demonstrated the overall increase in the detergency and whiteness by increasing the concentration of Citric acid which is utilized as a Builder. The soiled cloths before and after cleaning with the detergent samples were placed (rear as well as front face) in the Diffused Reflectance meter in order to detect the whiteness. Figure 8 indicates increase in the whiteness and efficiency of the detergent samples via graph.

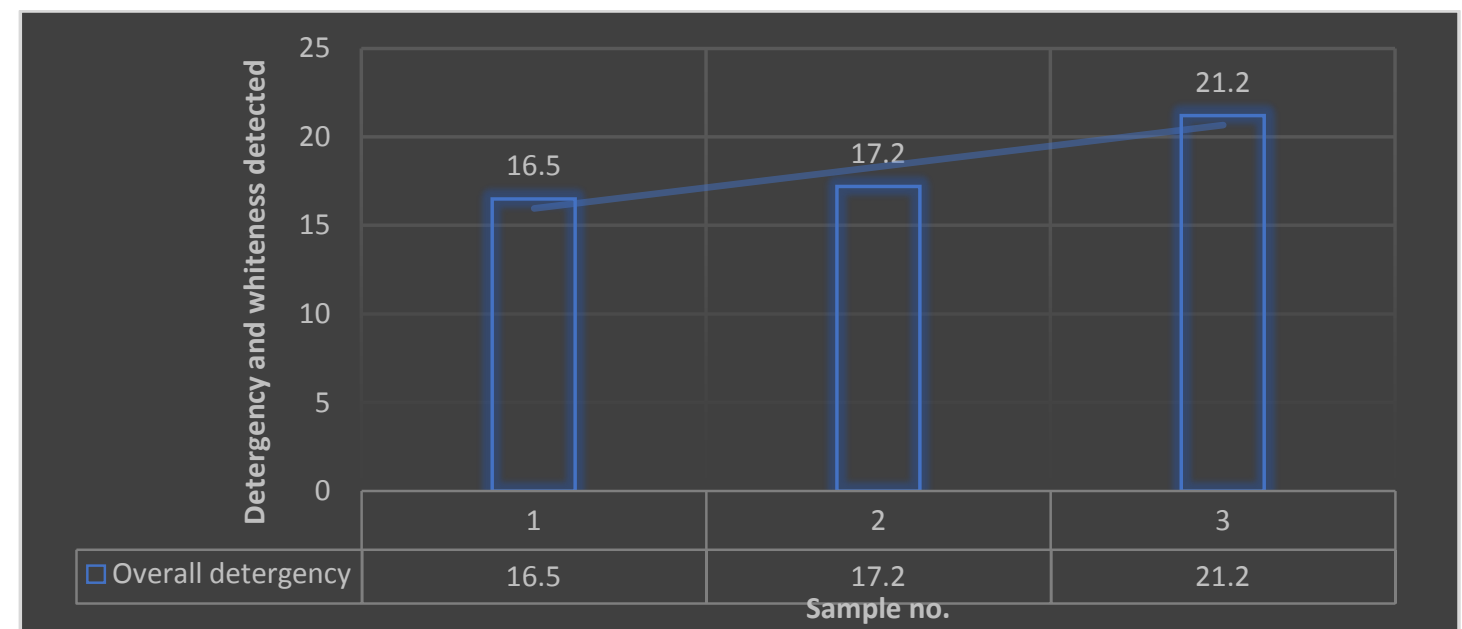

Fig 8. Overall increase in the detergency for three samples containing different percentage of citric acid.

The above graph was obtained from the data inputs of Table I. From the graph it can be inferred that there is an upward moving trend in the above demonstration as the percentage of builder was increased. In this test Citric acid was utilized as a Builder because of its easy availability as well as low cost. It was confirmed that the study was successful in retrieving the effectiveness of the detergent samples with a cost-effective Builder.

\section{CONCLUSION}

The activity of the Surfactants down at the nanoscale along with the other aspects are expected to enhance the detergency, however, $10 \%-20 \%$ of its activity is hampered because of the presence of hardness in the water which in turn hinders its sole purpose. Addition of builders is found to increase the detergent performance by removing the hardness in water and allowing the surfactant to perform its own designated task. After performing the experiments involving determination of hardness removed by different builders, we can conclude that Sodium Hexa meta phosphate and Citric acid are good substitutes for the conventional builder i.e. STPP. The detergency results for MES surfactant in the presence of Citric acid as a builder verified the improvement in the performance of the detergent. 


\title{
International Advanced Research Journal in Science, Engineering and Technology
}

Vol. 5, Issue 9, September 2018

Future work: Additional study can be carried out by trying to lower the values of the Critical Micelle Concentration of the surfactants so that the amount required in the detergent altogether gets deduced. Furthermore, this study can be carried out in the presence of temporary hardness. Effect of hardness on mixed surfactants can also be conducted as well as on the Builders.

\author{
Abbreviations: \\ LABSA- Linear Alkyl Benzene Sulphonic Acid. \\ MES- Methly Ester Sulfonate. \\ SLES- Sodium Laureth Sulphate. \\ SLS- Sodium Lauryl Sulphate. \\ AOS- Alpha Olefin Sulphonate. \\ CAPB- Cocamido Propyl Betaine. \\ STPP- Sodium Tripoluphosphate. \\ EDTA- Ethylene Diamine Tetraacetic Acid. \\ TEA- Triethanolamine. \\ TSPP- Tetra Sodium Pyrophosphate. \\ SHMP- Sodium Hexa Metaphosphate.
}

\section{REFERENCES}

[1]. Desando, M.A. and Reeves, L.W. Can. J. Chem. 64. 18171823 (1986).

[2]. Divya Bajpai, V.K Tyagi 2007, "Laundry Detergents: An Overview", Journal of Oleo Science 56, (7) 327-340.

[3]. ec.europa.eu/environment/water/pollution/phosphates/pdf/phosphates.pdf

[4]. http://web.utk.edu/ kcook/319S02/exp3m.pdf.

[5]. http://www.titrations.info/EDTA-titration-water-hardness

[6]. https://knowledge.ulprospector.com/3106/pc-surface-active-agents-surfactants/

[7]. https://www.cleaninginstitute.org/clean_living/soaps_detergents_products_ingredients_3.aspx

[8]. https://www.jstor.org/stable/25033295? seq=1\#page_scan_tab_contents

[9]. Roland Nagy, László Barthaa Judit Tóth, Árpád Vágó, 2014, "Study on Characteristics of Micelles Formed by Surfactants and Polymer Mixtures for Enhanced Oil Recovery." Chemical Engineering Transactions, Vol 36, 217-222 DOI: 10.3303/CET143603

[10]. www.borax.com/wp-content/uploads/2016/07/euf-borates-boratesindetergency.pdf

[11]. www.cosmique.in/pdf/MES-Brochure.pdf

[12]. www.ronaschemical.com/surfactant/PDF\%20file/Sodium\%20Alpha\%20Olefin\%20SulfateAOS.pdf

\section{BIOGRAPHIES}

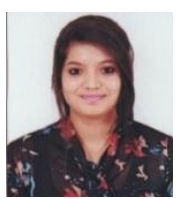

Miss Poonam Ghodke was born in Nagpur, India in 1996. She pursued Bachelor's degree in Chemical Engineering from Priyadarshini Institute of Engineering and Technology, RTM Nagpur University. She completed her A1 and A2 level German Proficiency in 2016-2017. She plans to study MS in Chemical Engineering and has keen interest towards research.

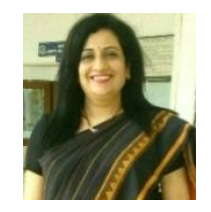

Dr. (Mrs.) Swarda Mote was born in Nagpur India, in 1964. She received the Bachelor in Chemical Engineering degree from the RTM Nagpur University in Year 1985 and the Master in Chemical Engineering degree from the RTM Nagpur University Nagpur, in Year,1994. She was awarded Ph.D in Chemical Engineering from RTM Nagpur University in 2015. Her research interests include waste water treatment, Environment \& Biotechnology, Chemical Engineering, Soaps and Detergents. 